Journal of Social Sciences 6 (3): 447-452, 2010

ISSN 1549-3652

(C) 2010 Science Publications

\title{
Relationships Between Background Factors and Female Marital Satisfaction
}

\author{
${ }^{1}$ Asghar Mirfardi, ${ }^{2}$ Ali Edalati and ${ }^{2}$ Ma'rof Redzuan \\ ${ }^{1}$ Faculty of Sociology, Yasooj University, Iran \\ ${ }^{2}$ Department of Human Development and Family Studies, Faculty of Human Ecology, \\ University Putra Malaysia, 43400 Serdang, Selangor, Malaysia
}

\begin{abstract}
Problem statement: In spite of the importance of marital satisfaction in couple relation, there is a little research in the Iranian context that examined the relationship between background factors and marital satisfaction. Thus, this study examined the relationship between duration of marriage, number of children, years of education and family income with female marital satisfaction. Approach: The study was carried out among a sample of 337 wives in Shiraz City, Iran. The Kansas Marital Satisfaction (KMS) was used to measure marital satisfaction. The study employed correlations test to determine the relationships between duration of marriage, number of children, years of education and family income with marital satisfaction. Results: The study found that there were no significant relationships between duration of marriage and family income and marital satisfaction. There was a negative significant relationship between respondents' age and number of children and marital satisfaction. There was a positive significant relationship between respondents' years of education and marital satisfaction. The Multivariate Regression Analysis was used to answer the last objective. The analysis showed that the predictor variable, women age, was found to be significant in explaining the observed variation in marital satisfaction (DV). Conclusion: Generally, the final model has explained $4 \%$ of total observed variance to marital satisfaction.
\end{abstract}

Key words: Female marital satisfaction, Kansas Marital Satisfaction, Iran

\section{INTRODUCTION}

Marital satisfaction means good feeling of marriage. Kaplan and Maddux (2002) stated that marital satisfaction is an individual experience in marriage which can only be evaluated by each person in response to the degree of marital pleasure. They believe that, it depends upon the individual's expectations, needs and desires in their marriage. Marital satisfaction refers to the degree of satisfaction between couples. This would mean the degree of satisfaction they feel with their relationship. This satisfaction could be addressed both from the perspective of wife toward the husband or the husband toward the wife.

In Iranian society, since women are economically dependent on their husbands, they are likely to stay with their husbands even if they are not satisfied with them. Moazami (2004) concludes that women keep living with their husbands in spite of being dissatisfied because of being economically dependent and fear of losing their children.

With respect to the context of the current Iranian condition, Shaditalab (2005) believes that at present times, women's level of dissatisfaction is related to their employment outside the house, marriage with non relatives, acquiring knowledge, equal cooperation of both partners in housework and opposition to polygamy. Among the educated women, it was found that the higher the educational level, the greater is the marital satisfaction. They have more hope and faith in life and there is more connection between their ideals and realities.

Gottman and Levenson (1999), in their study with 79 couples who were monitored in their discussion with one another and then were again monitored in their conversation four years later, understood that over time, the couples who were more faithful and not susceptible to change showed more positive effect in their communications with each other. Husbands presented themselves as more fixed over time in terms of treat with contempt, and for women, defensiveness remained fixed. Moreover, women had more positive and negative effect during conflict than men. They got more involved in positive communication and therefore seemed to consider it to be more important to maintain marital satisfaction in the relationship.

Corresponding Author: Ali Edalati, Department of Human Development and Family Studies, Faculty of Human Ecology, University Putra Malaysia, 43400 Serdang, Selangor, Malaysia Tel: +0060122793206 
Shachar (1991) studied marital satisfaction with a sample of 206 couples who were married up to four years for the first time. The result revealed a degree of modernity and liberalism and the husband's desire to marry were variables that had a significant effect on marital satisfaction.

Danesh and Heydarian (2006) investigated the relationship between mutual interest and respect among couples and their marital satisfaction. Result showed that couples and also men and women, who were more respectful and loved their spouses, were more satisfied in their marriage life. There was a positive correlation between the amount of respect and love among couples. The sample was 30 couples that were chosen by random cluster method.

With increasing level of education and mutual understanding, the level of aggression and dissatisfaction will decrease, as Mirahmadizadeh et al. (2003) argued that marital satisfaction was greater among those who had higher level of education at the time of marriage. It was greater among couples who have mutual respect for each other and hold both communication skills and more understanding. Attractiveness alone is less effective on marital satisfaction than positive attitude and understanding.

When the couples are more dissatisfied with their relation, they will most likely get divorce. In studying the rate of divorce, we can understand on how couple becomes satisfied or have conflict and aggression with their husband. Rajaei et al. (2007) studied in finding effective factors on marital satisfaction to reduce the rate of divorce. One hundred male and female married students and their spouses from Azad University responded to Hazan and Shaver's Attachment Style and Olson's Enrich inventories. Results revealed that between Anxious-Ambivalent attachment styles and marital satisfaction was negatively correlated, whereas the correlation between secure attachment and avoidant attachment was not found to be correlated. These results confirmed the necessity of psychological interventions before and throughout the marital life.

Thus, there is a need of more research in order to have a better understanding of the relationships between background factors and marital satisfaction among wives.

\section{MATERIALS AND METHODS}

The main objective of this study was to determine the relationships between duration of marriage, number of children, years of education, family income and female marital satisfaction. To achieve this objective, the study was carried out in Shiraz City, Iran. Shiraz
City, the central part of the Fars Province, has approximately the population of around 1,800,000 people.

The study employed survey design, where 346 married women involved in the study. The total population of this study has included 3510 married women who registered in different counseling clinics in Shiraz City. They were from various social groups and parts of Shiraz City. The number of respondents involved (sample size) was determined using a formula suggested by Krejcie and Morgan (1970). The population of the study includes all married women above 18 years of age. In order to obtain greater representation of the given population and decrease the probable sampling error, the study has utilized a stratified random sampling. The Shiraz City was divided into six regions and from each region a number of clinics were chosen randomly. From each clinic, the sample was chosen according the proportional number of women that were referred to. The selection of the respondents used simple random sampling technique, where the respondents were chosen randomly from the sampling frame (the list of names of the potential respondents in the particular clinic). From the clinics in region one, $53(15.31 \%)$ respondents were selected, region two $55(15.89 \%)$ respondents, region three 55 $(15.89 \%)$ respondents, region four 58 (16.76\%) respondents, region five 60 (17.34) respondents and region six 65 (18.78\%) respondents. After choosing the sample and obtaining written consent, the questionnaires were distributed among the sample in person and with the help of other colleagues who were experienced in conducting survey research. However, for those women who have been chosen as respondents, but refused to participate, they were replaced by other women in the same list in which they were selected randomly.

The Kansas Marital Satisfaction scale (KMS) (Schumm et al., 1986) was used to measure marital satisfaction. The satisfaction of the respondents towards their marital relationship was evaluated through this scale. It included three questions where responses range from 1 (extremely dissatisfied) to 7 (extremely satisfied). An example of the content of this questionnaire is: "How satisfied are you with your current marriage or relationship?" The sum of these three responses was the total score. This instrument is reported to have high internal consistency with alphas ranging from 0.89-0.98 and high inter-correlations among items ranging from 0.93-0.95 (Schumm et al., 1986). In this study, the level of marital satisfaction reported by women was used. Operationally marital satisfaction in this research refers to the degree of the 
wife's happiness with her marriage. In this study, the alpha reliability of women marital satisfaction was observed as 0.95 .

For data analysis, this study employed a correlation coefficient statistical analysis that investigates how scores on one variable or variables decrease or increase as there is a change in the scores of the other variable (s). Product-moment correlation was calculated to determine the degree of relationship. Positive correlation coefficient index (r) indicated a positive relationship, while a negative coefficient reflected otherwise. Meanwhile, Multivariate Regression Analysis was used to determine the contribution of female's background factors in explaining their marital satisfaction.

\section{RESULTS}

The descriptive data of the participants is provided in Table 1-3. The backgrounds of the respondents are illustrated in Table 1.

There are five background variables investigated in this study, namely, age, duration of marriage, education, number of children and family's total income. Table 1 reveals the frequency distribution of the variables. The Table 1 shows women's age from 1858 , with more than half of the women 199 (59.05\%) who were 30 years old and below. However, only a few respondents, i.e., $7(2.08 \%)$ were 50 years and above. As such, most of the respondents 317 (87.83\%) were below 40 years old. From the tabulated data and with respect to the observed values, it could be claimed that the age range of the married wives is appropriate according to the social norms of the context of this research. Moreover, the population is assumed to approaching normality where the values observed are $\mathrm{M}=30.77$ and $\mathrm{SD}=7.96$. The average age of 30 years for the respondents contributed to the appropriateness of the sampled population as well as the representativeness of the sample.

Moreover, educational background as an indicator of academic achievement of the respondents was also investigated. Based on the educational system of the context of this research, the first category was intended for primary school (1-5 years study), second category was secondary school (6-9 years), the third category was high school (10-13 years) and the final category was 14 years and above for university education. This classification was assumed to include all the participating wives in the research. Table 1 shows that most of the respondents have a high school degree $123(36.72 \%)$ and $116(34.62 \%)$ of them have a primary school degree. Approximately, 57 (17.01\%) have secondary school degrees. The lowest percentage of women education was $39(11.64 \%)$ belonging to university level.

Table 1: Background profile of the respondents

\begin{tabular}{|c|c|c|c|c|}
\hline Variables & $\mathrm{n}$ & $(\%)$ & $\mathrm{M}$ & SD \\
\hline Women age $(n=337)$ & & & 30.77 & 7.96 \\
\hline$<20$ & 20 & 5.93 & & \\
\hline $20-30$ & 179 & 53.12 & & \\
\hline $31-40$ & 97 & 28.78 & & \\
\hline $41-50$ & 34 & 10.09 & & \\
\hline$>50$ & 7 & 2.08 & & \\
\hline Women years education $(n=335)$ & & & 9.13 & 3.75 \\
\hline Primary school $(1-5)$ years & 116 & 34.62 & & \\
\hline Secondary school (6-9) years & 57 & 17.01 & & \\
\hline High school (10-13) years & 123 & 36.72 & & \\
\hline University and above (14 and above) years & 39 & 11.64 & & \\
\hline Duration of marriage $(n=337)$ & & & 9.62 & 9.09 \\
\hline$<5$ & 156 & 46.29 & & \\
\hline $5-10$ & 83 & 24.63 & & \\
\hline $11-15$ & 24 & 7.12 & & \\
\hline $16-20$ & 24 & 7.12 & & \\
\hline$>20$ & 50 & 14.84 & & \\
\hline \multicolumn{5}{|l|}{ Number of children $(n=337)$} \\
\hline$<2$ & 270 & 80.12 & & \\
\hline $2-4$ & 63 & 18.69 & & \\
\hline $5-7$ & 3 & 0.89 & & \\
\hline$>7$ & 1 & 0.29 & & \\
\hline Family income $($ Rials $)(n=332)$ & & & 450436 & 352681.83 \\
\hline$<200,000$ & 51 & 15.36 & & \\
\hline $200,000-400,000$ & 151 & 45.48 & & \\
\hline $400,001-600,000$ & 78 & 23.49 & & \\
\hline$>600,000$ & 52 & 15.66 & & \\
\hline
\end{tabular}




\section{J. Social Sci., 6 (3): 447-452, 2010}

Table 2: Correlation coefficient (r) between background profile and marital satisfaction

\begin{tabular}{ll}
\hline Backgound profile & Marital satisfaction \\
\hline Duration of marriage & -0.091 \\
Women age & $-0.171^{* *}$ \\
Number of children & $-0.118^{*}$ \\
Family income & -0.099 \\
Women education & $0.117^{*}$ \\
\hline
\end{tabular}

Table 3: Summary of regression analysis of the main variables contributing to marital satisfaction

\begin{tabular}{lllllll}
\hline $\begin{array}{l}\text { Predictors } \\
\text { of DV }\end{array}$ & $\begin{array}{l}\text { Unstandardized } \\
\text { coefficients }\end{array}$ & Std. error & $\begin{array}{l}\text { Beta } \\
\text { unstandardized }\end{array}$ & & \\
\hline Constant & 17.930 & 1.690 & & 10.609 & 0.000 \\
Women's Educ. & 0.138 & 0.085 & 0.089 & 1.621 & 0.106 \\
Women age & -0.123 & 0.054 & -0.169 & -2.273 & 0.024 \\
No. of children & 0.310 & 0.334 & 0.007 & 0.092 & 0.927 \\
\hline
\end{tabular}

From the tabulated data, it could be inferred that, the sample is normally distributed around the three levels of education in accordance with the current educational system in Iran, i.e., one-third have primary education, one-third have completed high school and have married and the rest either have quitted education before high school or have continued for the higher education to the universities. As observed in Table 1, most of the respondents have diploma education or above. High school education level and university level may indicate that it has played an effective role in enhancing and improving the level of women's knowledge and awareness due to education. Women have started to leave the traditional boundaries and are joining the social community. The high number of women at universities is evidence for the claim that they are more getting involved in social participations.

Another variable which has been investigated is the duration of marriage. The observed mean for duration of marriage is 9.62 years $(\mathrm{SD}=9.1)$. This could be interpreted as these couples have been living together for almost 10 years. However, 156 (46.29\%) of families have been living together for less than five years. Moreover, it was observed that $83(24.63 \%)$ have lived together for 5-10 years, 24 (7.12\%) of respondents have been living with each other for 1115 years and $24(7.12 \%)$ of them have lived with each other for 16-20 years. Finally it was observed that 50 respondents $(14.84 \%)$ have been living with each other for more than 20 years.

The number of children constituted the other variable in the current research. From the collected demographic questionnaire, it was found out that 270 $(80.12 \%)$ of the respondents had only one child or none. Another 63 (18.69\%) of the sample had 2-4 children. For the relatively large families it was observed that, $3(0.89 \%)$ had 5-7 children and one
(0.29\%) had more than seven children consecutively. More than $80 \%$ of the respondents had either no children or only one child. In the past, most families had many children and women were usually involved mainly in housekeeping duties and childcare. Nowadays, with an increase in the level of education, children are viewed differently. Having children, especially male children, is no longer a general basis for Iranian families. Many families are satisfied with having two children, regardless of the gender. The improvement in education level as well as propaganda from the government has caused families to pay more attention to the quality of childcare rather than the quantity and gender. Contrary to the past, many families are nuclear rather than extended.

Another variable was the "total of family income". The observed mean for the family income was 4504,360 (in Iranian currency, Rials) and its standard deviation was observed 352,681.83, which was relatively far from the observed mean of 450,436 . Therefore, it can be inferred that the sample of the current research are abnormally scattered as far as their level of total family income is concerned.

There were $51(15.36 \%)$ respondents who had an income less than 2,000,000 Rials. The majority of family's income was in the category of 2,000,000$4,000,000$, i.e., 151 respondents $(45.48 \%)$ and 78 $(23.49 \%)$ of them have a monthly income of $4,000,001-$ $6,000,000$ Rials. The other members of the sample, i.e., $52(15.66 \%)$ have an income of more than $6,000,000$ Rials. A review of the Labor Regulations in 2008 shows that this is within the normal ranges as in Iran the minimum wage is 3,000,000 Rials for workers and employees (Ministry of Labor and Social Affairs, 2008). As such, all family incomes fall under the middle area of normal curve. However, these families are not socially classified as rich based on their level of income.

The category of income shows that most of the families had either an average or low income. Approximately $85 \%$ of them have a monthly income rate lower than 6,000,000 Rials. This is an average income rate for Iranian families. The high income class and low income class comprised of $15 \%$ of the whole society. Thus, in terms of income, the sample of this study was normal. According to the Ministry of Labor and Social Affairs (2008), the employers must pay a minimum monthly income of 3,000,000 Rials.

The Pearson's Product-Moment Correlation Test was used to test the relationships between background of the respondents and their marital satisfaction. Table 2 shows the results of the analysis. The results could be summarized as follows: 


\section{J. Social Sci., 6 (3): 447-452, 2010}

- There is no significant relationship between respondents' duration of marriage and marital satisfaction, where $r=-0.091, p>0.05$

- There is a negative significant relationship between respondents' age and marital satisfaction, where $r=-0.171, p \leq 0.05$

- There is a negative significant relationship between respondents' number of children and marital satisfaction, where $r=-0.118, p \leq 0.05$

- There is no significant relationship between respondents' family income and marital satisfaction, where $r=-0.099, p>0.05$

- There is a positive significant relationship between respondents' years of education and marital satisfaction, where $r=0.117, p \leq 0.05$

Table 3 shows the result of the Multivariate Regression Analysis was used to answer the last objective. It shows that only one predictor variable, i.e., women age, was found to be significant in explaining the observed variation in marital satisfaction (dependent variable). Generally, the final model has explained only $4 \%$ of total observed variance to marital satisfaction $\left(\mathrm{R}^{2}=0.04\right)$.

\section{DISCUSSION}

The rationale of the current study is to examine the relationships between duration of marriage, number of children, years of education and family income with female marital satisfaction. The study found that there were no significant relationships between duration of marriage and family income with marital satisfaction. However, there were negative significant relationships between respondents' age and number of children and marital satisfaction. And also, there was a positive significant relationship between respondents' years of education and marital satisfaction.

Marital satisfaction is one of the most important factors that play a great role in marital life in all societies. Marital satisfaction means good feeling of marriage. Normally, before getting marriage women have some ideals and dreams about their new relationship of marriage. However, in the Iranian society, the relationship between women and men before marriage is limited and controlled, especially by the government and families, and it is believed that it could lead to marital dissatisfaction among marriage couples, since their marriage is not based on love. The marital dissatisfaction would contribute to relatively high divorce rate in the society. For example, the rate of divorce for Tehran City was $25 \%$ and for Shiraz City was $20 \%$. Moreover, nowadays in Iran, women are more educated. Through education, they discover and learn new family values of the society and the world. They are more aware about their rights and lives in the society.

\section{CONCLUSION}

Iranian society is passing from a traditional to a modern society. In this situation, women face more difficulty and problem compare to men. With the increased level of their knowledge and involvement in employment, they become more participative in social activities, which could lead them to have more contacts with men before marriage. In other words, they are more exposed to new culture and values related to their right as women and also are more liberated to choose their partners. The arranged marriage is no more common in Iran. Hopefully, this could lead to marital satisfaction and less conflict during their marital life.

There were some limitations in this research. The study was not able to focus on men because they were not easily accessible, where only women were referred to clinics for consultation and counseling. However, this kind of research is rarely carried in Iranian society, thus the results of this study could be beneficial to several researchers and policymakers. It is suggested that future research may include longitudinal comparison between the levels of male and marital satisfaction.

It is imperative for the government and those other sections of organizations that deal with women to establish a training program for young generation who wish to get marriage in order to make them aware about the various factors and variables necessary in achieving satisfaction in their marital life. If the level of marital satisfaction is increased, families are expected to have better condition and a healthy atmosphere for parents to raise their children.

\section{ACKNOWLEDGEMENT}

The researchers would like to thank Dr. Kennedy for editing and reviewing this study. The comments greatly improved the manuscript.

\section{REFERENCES}

Danesh, E. and M.M. Heydarian, 2006. The relationship between mutual interest and respect among couples and their marital satisfaction in Qom city. J. Counsel. Res. Dev., 5: 59-76.

Gottman, J.M. and R.W. Levenson, 1999. What predicts change in marital interaction over time? A study of alternative methods. Fam. Process, 38:143-158.DOI: $10.1111 /$ j.1545-5300.1999.00143.x 
Kaplan, M. and J.E. Maddux, 2002. Goals and marital satisfaction: Perceived support for personal goals and collective efficacy for collective goals. J. Soc. Clin. Psychol., 21: 157-164. http://cat.inist.fr/?aModele $=$ afficheN\&cpsidt $=1369$ 5553

Krejcie, R.V. and D.W. Morgan, 1970. Determining sample size for research activities. Educ. Psychol. Measur., $\quad 30$ : 607-610. http://www.usd.edu/ mbaron/edad810/Krejcie.pdf

Ministry of Labor and Social Affairs, 2008. Wage of labor. IRIMLSA. http://www.irimlsa.ir

Mirahmadizadeh, A.R., N. Nakhai Amroodi, S.H. Tabatabai and R. Shafieian, 2003. Marital satisfaction and related determining effectual factors in Shiraz. J. Psychiatry Clin. Psychol., 8: 56-63.

Moazami, S., 2004. Crime and violence in the family. J. Female Res., 2: 39-53.
Rajaei, A.R., M. Nayeri and S.H. Sedaghati, 2007. Attachment styles and marital satisfaction. J. Iran. Psychol., 3: 347-356.

Shachar, R., 1991. His and her marital satisfaction: The double standard. Sex Roles, 25: 451-467. DOI: 10.1007/BF00292534

Shaditalab, J., 2005. Iranian women: Rising expectations. Middle East Critique, 14: 35-55. DOI: 10.1080/10669920500057005

Schumm, W.R., L.A. Paff-Bergen, R.C. Hatch, F.C. Obiorah and J.M. Copeland et al., 1986. Concurrent and discriminant validity of the Kansas marital satisfaction scale. J. Marriage Fam., 48: 381-387. http://www.jstor.org/pss/352405 